\title{
Silicate Island Formation in Gas Metal Arc Welding
}

\author{
An electromagnetic levitation system was used to study \\ the growth kinetics of the silicate islands
}

\author{
BY R. DERRIEN, E. M. SULLIVAN, S. LIU, E. MOINE, AND F. BRIAND
}

\begin{abstract}
Because formation of silicate islands during gas metal arc welding is undesirable due to decreased productivity and decreased quality of welds, it is important to understand the mechanism of the formation of these silicate islands to mitigate their presence in the weld. The effects of welding parameters on the silicate formation rate were studied. Results showed that the applied voltage and oxidizing potential of the shielding gas were the parameters that most strongly influenced the amount of silicates formed on the surface of the weld bead. High-speed video was used to observe the formation of silicate islands during the welding process, which showed that the silicates were present at each stage of the welding process, including the initial melting of the wire electrode, and grew by coalescence. A flow pattern of the silicate islands was also proposed based on video analysis. An electromagnetic levitation system was used to study the growth kinetics of the silicate islands. Silicate coverage rate was found to increase with increasing oxidizing time, increasing oxidizing potential of the atmosphere, and increasing content of alloying elements except for Ti.
\end{abstract}

\section{KEYWORDS}

- Gas Metal Arc Welding • Silicates • Flux-Cored Wires - Oxidation Kinetics

\section{Introduction}

Gas metal arc welding (GMAW) is an automatic or semiautomatic welding process involving the establishment and sustainment of a gas-shielded electric arc between a continuously fed, consumable wire electrode and the metallic components to be joined. Given the relative ease and speed of the GMAW process, this type of welding has found widespread use in the welding industry. The shielding gas and the welding wire electrode are the two primary components of the GMAW process that can be altered to influence the properties of the weld. Various types of consumable wire electrodes are used in GMAW, including solid alloy wires and cored wires, which consist of a metal alloy sheath containing a powdered mixture of alloying elements, metals, and minerals to impart certain properties to the weld. Welding with electrodes of certain compositions can lead to the formation of silicate islands (Refs. 1-7) on the surface of the weld bead, which can result in inclusions within the weld bead during multipass welding (if thorough cleaning is not performed) and the formation of pores, both of which can impair the mechanical performance of the welded joint. Silicate islands also cause arc destabilization during welding due to their low electrical conductivity. The number of silicates formed, the degree of silicate adhesion to the weld bead, and the position of the silicate islands on the weld bead all depend on the welding process parameters (Refs. 8-13). The removal of these silicate particles from the bead surface, whether in single pass or multipass welding, becomes imperative. The added processing step also adds cost to the manufacturing process.

To mitigate the formation of silicates on the weld bead surface, an understanding of the underlying mechanisms of their formation is required. Particularly, the chemical reactions that occur during the welding process will directly govern the formation of silicate islands. The flow of these reaction products in the molten weld pool will determine the spatial distribution of the silicate islands on the surface or the interior of the solidified weld.

\section{Chemical Reactions Occurring in GMAW}

The composition of a weld is directly influenced by the composition of the molten base metal and the composition of the metal contributed by the melting of the electrode. During the GMAW process, chemical reactions occur during the growth of the metal droplet at the electrode tip, during the transfer of the metal droplet to the weld pool, and within the weld pool itself. The first two steps described above occur in the welding arc. To categorize the chemical reactions, the weld system can be separated into the following four regions of interest: 1) The molten electrode tip; 2) the detached metal droplet; 3) the hot weld pool directly under the arc; and 4) the cold, solidifying weld pool. These regions are illustrated schematically in Fig. 1. 


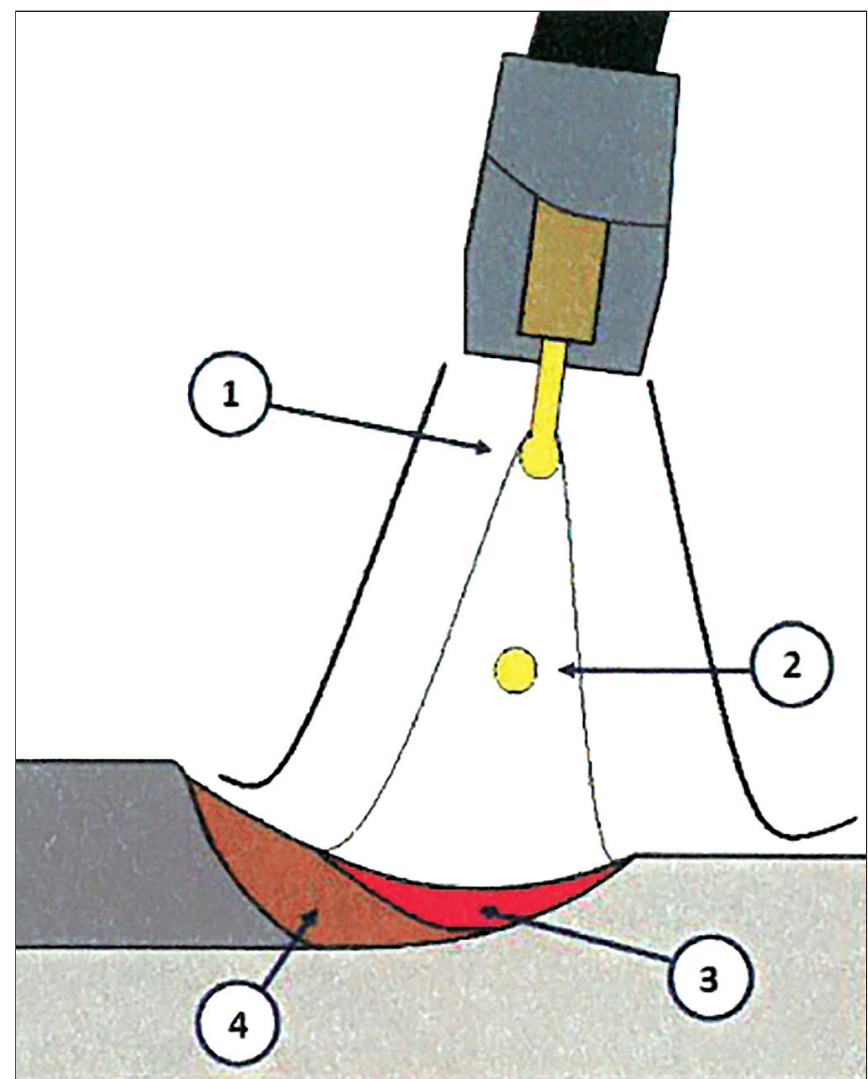

Fig. 1 - Illustration showing the four distinct regions of a gas metal arc weld: 1) The molten electrode tip; 2) the detached metal droplet; 3) the hot weld pool directly under the arc; 4) the cold, solidifying weld pool.

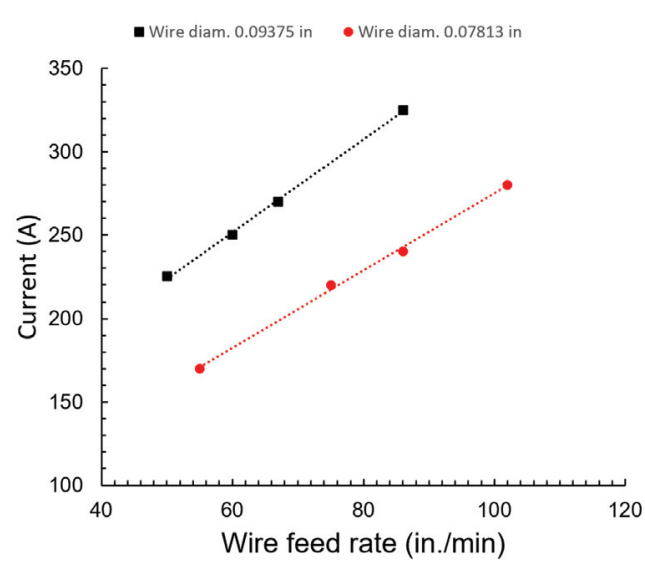

Fig. 3 - Welding current (A) vs. wire feed rate (in./min) for steel powder-cored wires used in GMAW under similar conditions to those in this study.

The molten electrode tip has the highest temperatures of the weld system due to the high current density. As such, there is a greater driving force for the occurrence of thermochemical and electrochemical reactions at the electrode tip; consequently, the reactions at the electrode tip are expected to have the largest influence on the weld metal composition. Once a molten droplet is detached from
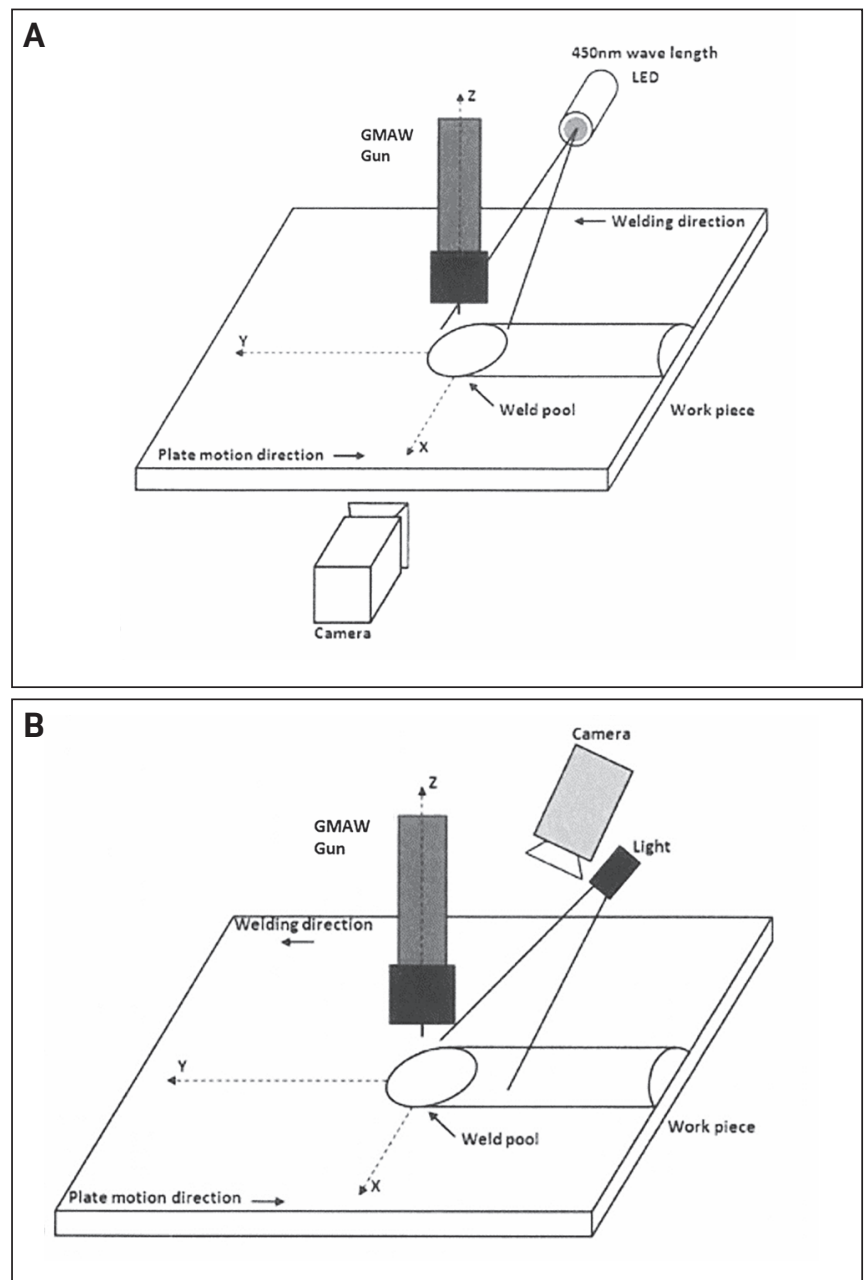

Fig. 2 - Schematic setup of the high-speed video recording system: A - Setup includes monochromatic LED lighting to record the arc behavior and weld pool from the side; $B-$ setup captures the weld pool flow from above.

the electrode tip, it becomes electrically neutral. Only thermochemical reactions continue, and the extent of the reactions will depend exclusively on the chemical composition of the droplet, the chemical potentials of the different species found in the arc, the time of flight of the droplet from the electrode tip to the molten weld pool, and the temperature of the droplet. Grong et al. (Ref. 10) established two distinct regions of the weld pool, hot and cold, according to the relative temperatures of these regions. In the weld pool region immediately under the electrode, the temperature is expected to be high, and thus will constitute the hot region of the weld. The cold region will be located in the trailing edge of the weld pool. In the hot portion of the weld pool, both thermochemical and electrochemical reactions can occur, and oxidation and reduction may take place simultaneously.

Due to the strong turbulence in the molten weld pool, temperature-induced density differences in the molten metal, and density differences between the molten metal and reactions products, the resulting reaction products (e.g., oxides, nitrides, or sulfides) are separated from the molten metal. The particles will flow in the molten pool 


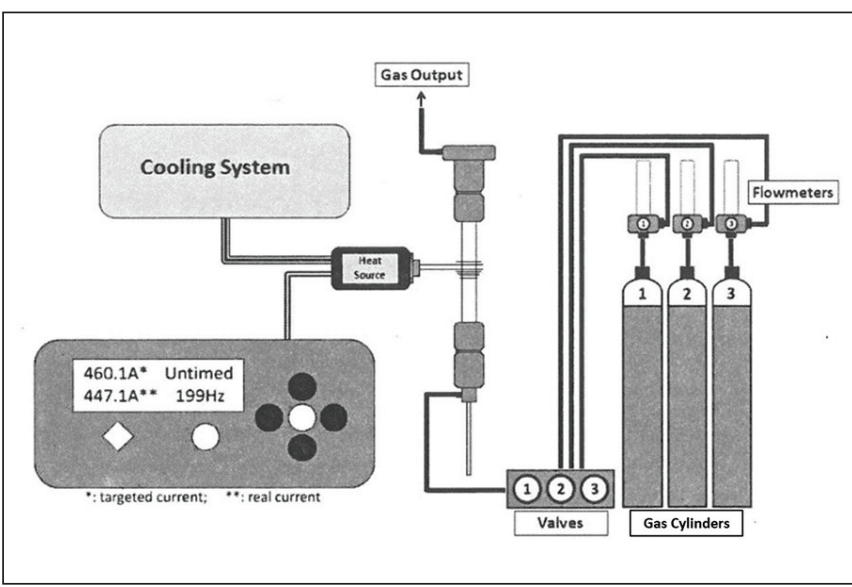

Fig. 4 - Schematic setup of the EML system. The power source used was an EASYHeat 3542 HV AT capable of $4.2 \mathrm{~kW}$.

following the natural convection of the weld pool, from the hot to the cold region. Additionally, in the cold portion of the weld pool, further reactions are expected to continue since alloying elements are expected to form oxides from the dissolved oxygen in the metal due to decreasing solubility of both species. Thus, oxides formed in this region tend to remain in the weld bead as a result of the lower turbulence here. In GMAW, the direct current electrode positive (DCEP), or "reverse polarity," is commonly used. In this situation, the negatively charged workpiece emits electrons, which enter the electrode, imparting about $2 / 3$ of the welding process heat to the electrode. The melting of the electrode may also cause metal ions to be emitted from the electrode, which then travel to the workpiece (Ref. 14). Metal ions with a greater resistivity will have more interaction with the electrons in the arc, which leads to higher resistivity metal ions to concentrate at the positively charged electrode while the lower resistivity metal ions tend to migrate towards the negatively charged workpiece. This phenomenon governs the reactions that then occur at the electrode and workpiece.

The reaction between silicon, which is a main ingredient of the silicate islands in GMA welds, and oxygen in the cold zone of the weld pool can be described by the following three reactions below (Ref. 15).

$$
\begin{gathered}
{[\mathrm{Si}]+2[\mathrm{O}] \rightarrow \mathrm{SiO}_{2}} \\
\mathrm{SiO}_{2}+2[\mathrm{M}] \rightarrow[\mathrm{Si}]+2 \mathrm{MO} \\
\mathrm{Si}_{2} \mathrm{O}+\mathrm{MO} \rightarrow 2 \mathrm{SiO}^{-}+\mathrm{M}^{2+}
\end{gathered}
$$

In these equations, square brackets represent elemental concentrations dissolved in the molten iron, charged formulae represent ionic species in the form of slag, and all other neutral formulae represent chemical compounds in different stages of reaction. The reactions involving silicon can be paired with reactions of other alloying elements $(M)$ to identify the silicate-forming reactions. It is likely other reactions are occurring in the region between the electrode tip and the molten weld pool with the formation of a number of silicates (e.g., $\mathrm{MnO}_{\mathrm{SiO}}, \mathrm{MgO} . \mathrm{SiO}_{2}, \mathrm{TiO}_{2} \mathrm{SiO}_{2}$ ([Ref. 1]). In GMAW of steel, the silicates that form are commonly Feand Mn-containing (Refs. 4, 5, 16).

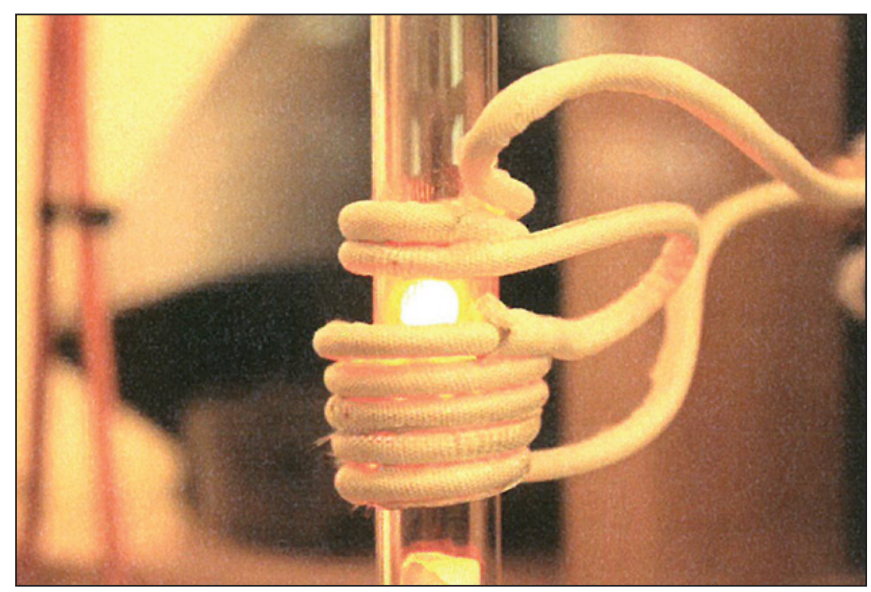

Fig. 5 - The induction coil and levitation chamber used in the electromagnetic levitation experiments.

\section{Experimental Methods}

Multiple experimental setups were used to study and characterize the formation of silicate islands during GMAW. A high-speed video system was used to observe the behavior of the silicate islands at different stages of the welding process. Several iterations of welding experiments and weld analyses were also performed to determine the effect of welding parameters on the formation of silicate islands. An electromagnetic levitation (EML) system was used to examine the effects of various shielding gas compositions on the oxidation of molten metal droplets.

\section{Calculation of Silicate Formation Rate}

The silicate formation rate (SFR) is an indicator of the amount of silicate produced during the welding process, yielding the mass of silicate formed per $100 \mathrm{~g}$ of welding consumable used. Therefore, the silicate formation rate can be used to compare the propensity of different welding consumables in exhibiting silicate islands on the weld surface. Immediately after welding, an aluminum sheet was placed over the weld to prevent silicate islands from being ejected away from the weld bead surface following solidification and during cooling of the weld metal. Even if ejected, the particles would tend to remain on the weld surface under the aluminum foil tent. After cooling, the silicate islands were removed from the weld bead and weighed to within a tenth of a milligram. The SFR was then calculated by using Eq. 1,

$$
\operatorname{SFR}(\%)=100 \% \cdot W_{s} / T_{s} \cdot \mathrm{WFR} \cdot W_{w}
$$

where $W_{s}$ is the weight of the silicate recovered from the weld, $T_{s}$ is the elapsed welding time starting from arc initiation, WFR is the wire feed rate, and $W_{w}$ is the linear density of the welding wire $(\mathrm{g} / \mathrm{m})$, which is measured by weighing small wire segments of a known length. It should be noted that the WFR also dictates the welding current. The SFR values obtained for different weld systems (similar consumable but different welding parameters or filler metals) are then compared to determine the relative propensity of silicate island formation of each system. 


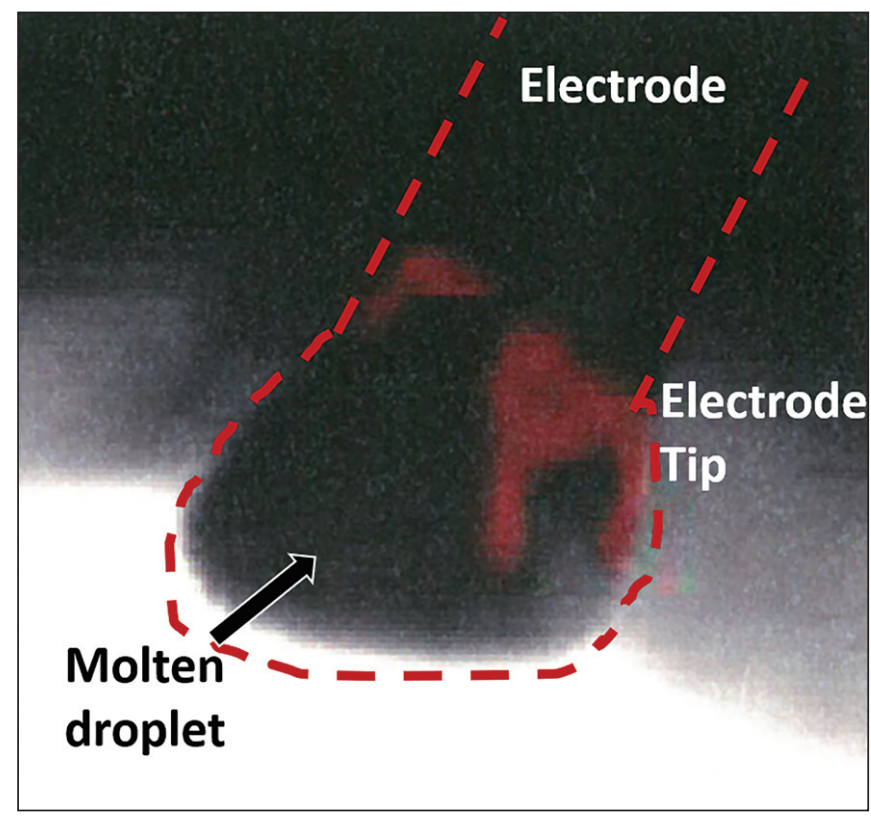

Fig. 6 - Still frame from the high-speed video recording of the electrode tip during GMAW. Silicate particles can be seen (artificially colored red) on the surface of the melted electrode tip.

\section{High-Speed Video Camera System}

To closely observe the behavior and formation of the silicate islands during GMAW, an AOS X-PRI high-speed video camera was used to record the metal droplet transfer and weld pool fluid flow during welding - Fig. 2. In Fig. 2A, the GMAW gun and the camera were both kept stationary while the weld plate was translated by a Bug-O GO-FER III carriage unit. To reduce the glare from the arc, a 450-nmwavelength LED was used in conjunction with a camera filter that only allowed transmission of 450-nm light. The setup shown in Fig. 2B was used to film the movement of the silicate islands on the surface of the weld pool. In this setup, a high-intensity white light was used to illuminate the weld pool. The camera was positioned such that the gun nozzle obscured the arc to improve the quality of the images.

\section{Materials}

For the examination of the SFR for different welding parameters, several different welding wire compositions and shielding gases were used. The base metal in each welding experiment was ASTM A709 Grade 36 steel of 1 cm (0.4 in.) thickness.

Table 1 lists the different chemical compositions of the shielding gases used in this study. The different $\mathrm{O}_{2}$ and $\mathrm{CO}_{2}$

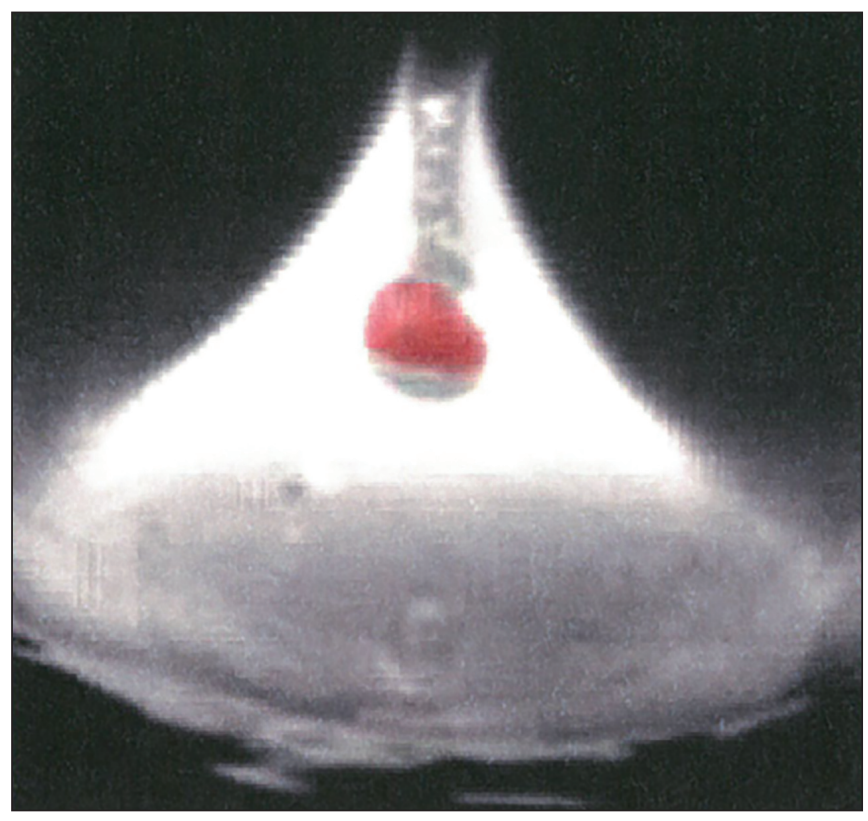

Fig. 7- Still frame from a high-speed video recording showing the presence of silicates (artificially colored red) on the surface of the droplet detached from the electrode during GMAW.

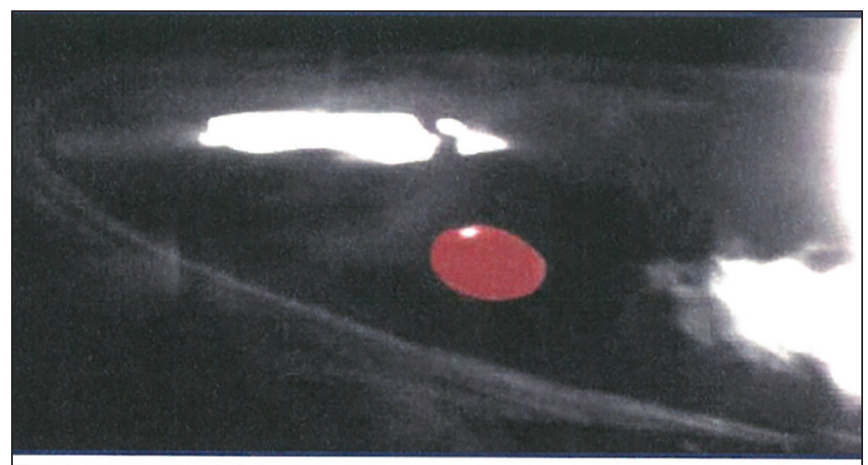

\section{Welding Direction}

Fig. 8 - Still frame from a high-speed video recording showing silicates (artificially colored red) floating on the surface of the "cold" weld pool during GMAW.

contents provided different oxidation potentials to the shielding gases, which were expected to result in different amounts of silicate formation. Each of the wires contained a metal powder blend as the core ingredient. Tables 2 and 3 give the chemical compositions of the various welding wires used. The experimental cored wires were prepared on a wire mill at the Colorado School of Mines, Golden, Colo., specifically to examine the effects of silicon, manganese, alu-

\begin{tabular}{|c|c|c|c|}
\hline \multicolumn{4}{|c|}{ Gas Composition } \\
\hline $25 \% \mathrm{CO}_{2}-75 \% \mathrm{Ar}$ & $5 \% \mathrm{O}_{2}-95 \% \mathrm{Ar}$ & $10 \% \mathrm{He}-90 \% \mathrm{Ar}$ & $10 \% \mathrm{CO}_{2}-5 \% \mathrm{O}_{2}-85 \% \mathrm{Ar}$ \\
\hline $10 \% \mathrm{CO}_{2}-90 \% \mathrm{Ar}$ & $2 \% \mathrm{O}_{2}-98 \% \mathrm{Ar}$ & $5 \% \mathrm{He}-95 \% \mathrm{Ar}$ & $2 \% \mathrm{O}_{2}-8 \% \mathrm{He}-90 \% \mathrm{Ar}$ \\
\hline
\end{tabular}



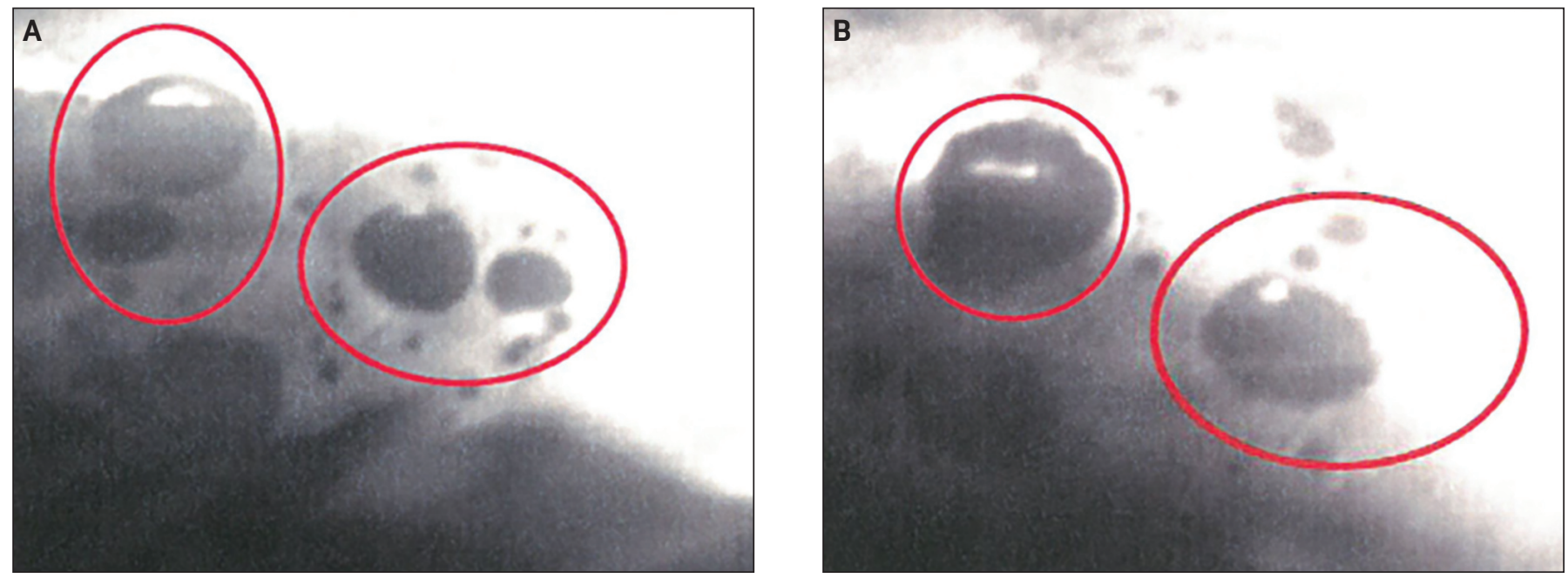

Fig. 9 - Still frames from a high-speed video recording of GMAW showing four silicate particles A) before and B) after coalescence into two silicate islands.

minum, and titanium on SFR. Each wire had a diameter of $1.14 \mathrm{~mm}$ (0.045 in.) except for wire $\mathrm{E}$, which had a diameter of $1.4 \mathrm{~mm}$ (0.055 in.). The compositions of the wires made at Colorado School of Mines are given in Table 2 and were calculated via mass balance using the known composition of the powder core and the wire sheath. The compositions of additional cored wires prepared by the Technical Centre for Welding Applications of Air Liquide in Paris, France, are given in Table 3. The diameters of these wires are given in Table 4.

Figure 3 shows the welding current vs. WFR for metal powder-cored wires in GMAW under similar conditions to those used in this work. The welding parameters used for the determination of the effect of WFR and polarity on SFR are given in Tables 5 and 6 and were extracted from the data given in Fig. 3.

\section{Electromagnetic Levitation System}

The kinetics of silicate formation under different shielding gases were examined using an EML system. Such a system allows the formation of the silicate islands to be observed in the absence of a substrate, which could potentially react with the molten metal droplet. The system consists of a cooling unit, a power supply, a gas flow system, and a levitation chamber - Fig. 4. The cooling unit flows water through the copper induction coil to avoid melting of the coil while the power supply provides the current to induce the electromagnetic field for levitation. The gas system consists of three separate gas flows for the control of the composition and the flow rate of gas through the levitation chamber. Helium, which has a high thermal conductivity, was used to control the temperature of the droplet sample.

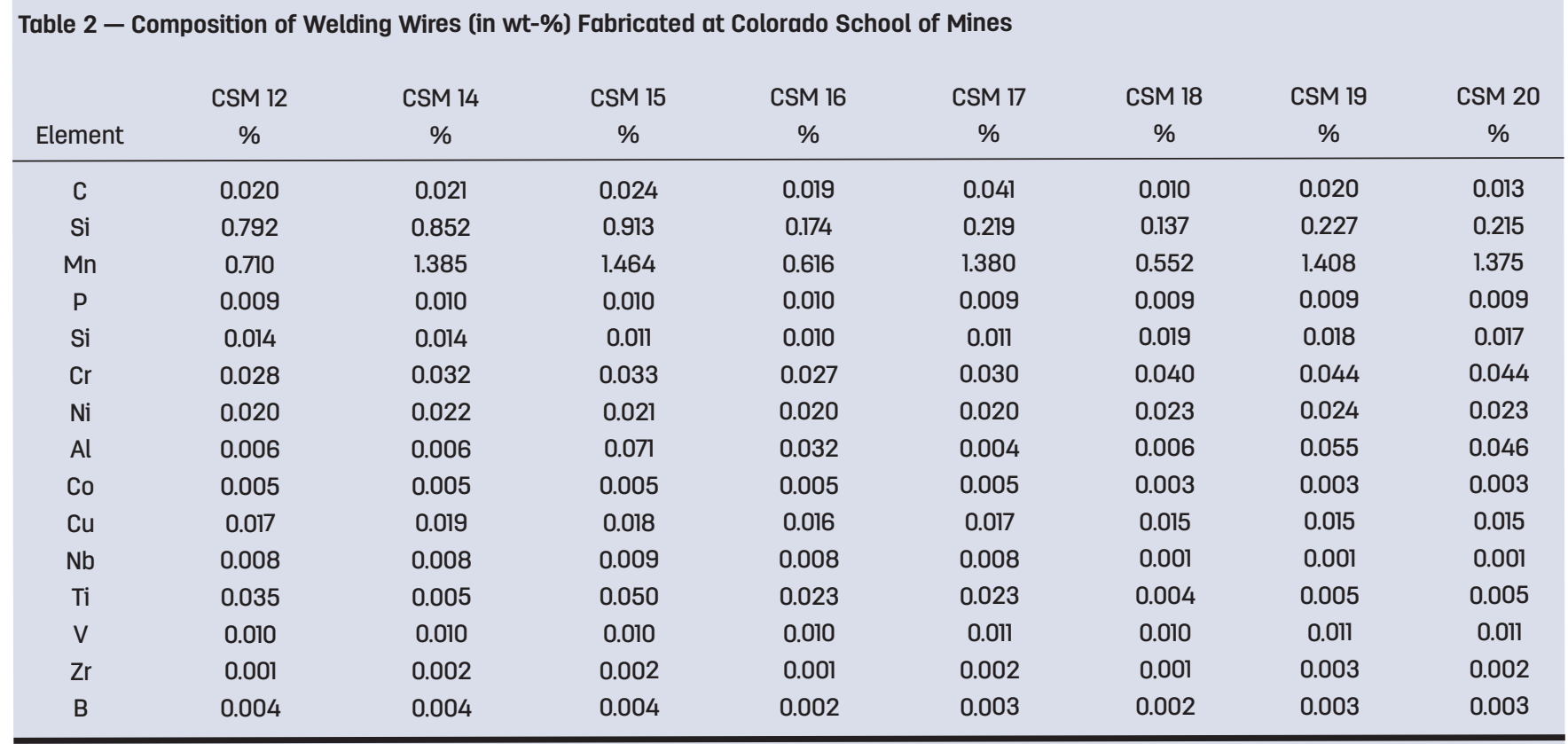



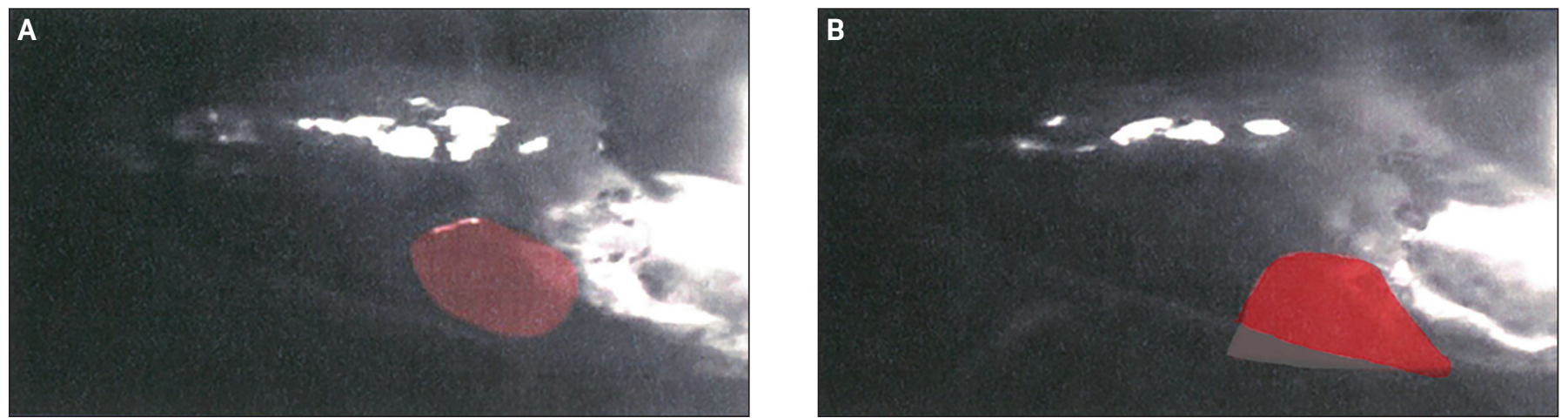

Fig. 10 - Still frames from the high-speed video recording showing a silicate island: A - Before attachment floating on the surface of the weld pool); B - after attachment to the edge of the weld pool.

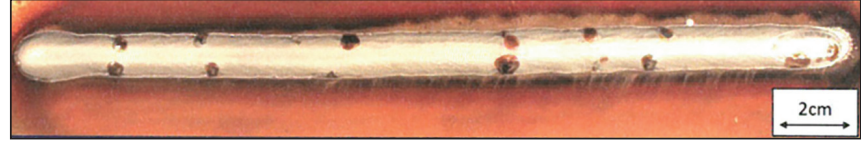

Fig. 11 - Photograph of a weld with silicate islands present on the surface and along the edge of the bead.

Argon was used with $\mathrm{O}_{2}$ or $\mathrm{CO}_{2}$ in varying amounts to provide gas atmospheres of various oxidation potentials.

The levitation chamber was a borosilicate glass tube with an outer diameter of $15.87 \mathrm{~mm}$ (0.625 in.) and an inner diameter of $12.72 \mathrm{~mm}$ (0.501 in.). The induction coil was wrapped around the chamber, as shown in Fig. 5. Shielding gas flowed up from the bottom of the chamber, helping to support the levitating droplet. A Metis MS09 pyrometer with a spot size of $0.35 \mathrm{~mm}$ was used to monitor the temperature of the droplet. The average mass of the droplet samples was measured to be $1.5 \mathrm{~g}$. The droplets were obtained by the inert gas arc button melting of segments of the welding wires.

The droplets were maintained in a molten state under different gases for varying lengths of time ( 0 to $25 \mathrm{~s}$ ) to examine the kinetics of silicate island formation on the droplets. A high-speed video camera was used to record the flow behavior of the molten metal and silicates during levitation. After levitation and upon solidification, the surface area of each droplet that was covered by silicates was measured.

\section{Results and Discussion}

\section{Silicate Island Flow within the Weld Pool}

Figure 6 is a still frame extracted from the high-speed video of the electrode tip exhibiting globular transfer during GMAW. The diameter of the molten tip shown was larger than that of the electrode. A silicate layer (colored red artificially in the photograph) was clearly present in the "neck" of the melted portion of the electrode. The silicate particles tend to concentrate in the neck due to fluid flow on the surface of the droplet and the lower density of the silicate particles. Such motion causes the silicate particles to grow and coalesce. Subsequently, the silicates attach to the solid part of the electrode wire tip, which is at a lower temperature than the molten droplet. The flow behavior observed in these experiments is similar to that predicted by Wang's modeling work (Ref. 17). The initial for-

Table 3 - Composition of Welding Wires (in wt-\%) Supplied by Air Liquide

\begin{tabular}{|c|c|c|c|c|c|c|}
\hline Element & $\begin{array}{c}\text { Wire A } \\
\quad \%\end{array}$ & $\begin{array}{l}\text { Wire B } \\
\quad \%\end{array}$ & $\begin{array}{c}\text { Wire C } \\
\quad \%\end{array}$ & $\begin{array}{l}\text { Wire D } \\
\quad \%\end{array}$ & $\begin{array}{l}\text { Wire } \mathrm{E} \\
\quad \%\end{array}$ & $\begin{array}{c}\text { A36 (base metal) } \\
\%\end{array}$ \\
\hline C & 0.060 & 0.010 & 0.060 & 0.096 & 0.065 & 0.190 \\
\hline $\mathrm{Si}$ & 0.430 & 0.770 & 0.830 & 0.770 & 0.640 & 0.230 \\
\hline $\mathrm{Mn}$ & 0.910 & 1.290 & 1.330 & 1.430 & 1.520 & 0.770 \\
\hline $\mathrm{P}$ & 0.012 & 0.010 & 0.008 & 0.012 & 0.012 & 0.015 \\
\hline$S$ & 0.008 & 0.019 & 0.010 & 0.010 & 0.019 & 0.040 \\
\hline $\mathrm{Cr}$ & $<0.01$ & 0.035 & $<0.01$ & 0.022 & 0.024 & 0.200 \\
\hline $\mathrm{Ni}$ & 0.010 & 0.024 & 0.010 & 0.015 & 0.019 & 0.160 \\
\hline $\mathrm{Al}$ & $<0.1$ & 0.002 & $<0.01$ & 0.002 & 0.004 & 0.000 \\
\hline Co & $<0.01$ & 0.006 & $<0.01$ & 0.005 & 0.005 & 0.000 \\
\hline $\mathrm{Cu}$ & 0.210 & 0.018 & 0.250 & 0.087 & 0.310 & 0.340 \\
\hline $\mathrm{Nb}$ & $<0.01$ & 0.008 & $<0.01$ & 0.011 & 0.007 & 0.000 \\
\hline $\mathrm{Ti}$ & $<0.01$ & 0.005 & $<0.01$ & 0.011 & 0.180 & 0.000 \\
\hline v & $<0.01$ & 0.007 & $<0.01$ & 0.003 & 0.003 & 0.005 \\
\hline $\mathrm{Zr}$ & 0.000 & 0.001 & 0.000 & 0.003 & 0.001 & 0.000 \\
\hline
\end{tabular}




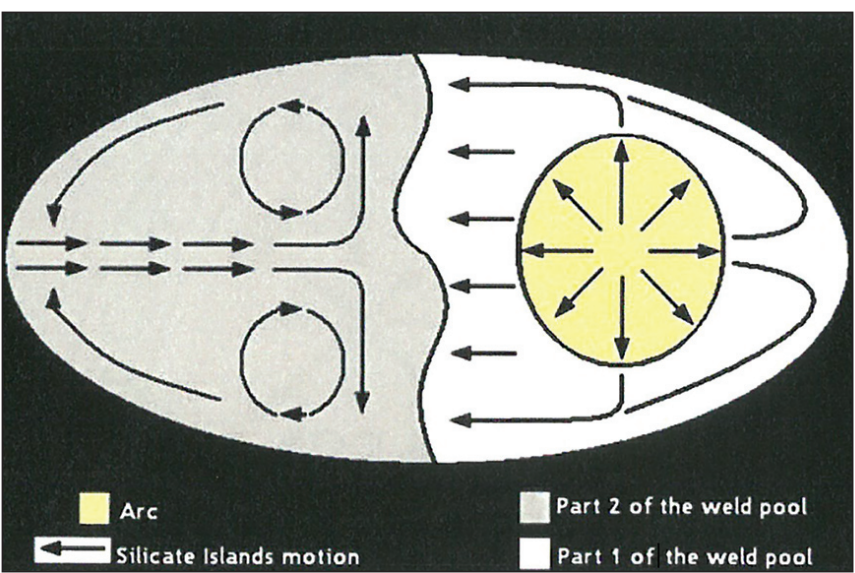

Fig. 12 - Schematic diagram of the observed flow pattern of the silicate islands on the surface of the weld pool. The gray area indicates the presence of an oxide layer.

mation of the silicates in the molten electrode is conceptualized the following way: upon melting, the elements present in the filler wire and the wire core $(\mathrm{Mn}, \mathrm{Ti}, \mathrm{Mg}, \mathrm{Ca}$, etc.) capture oxygen from the surrounding atmosphere, and small groups of silicates form. The convective forces in the molten droplet caused these silicate groups to interact and coalesce into the large islands present on the molten electrode tip seen in the videos. Once the droplet detached, it was seen that the silicates attached to the solid wire separated in two (Fig. 7); one part remained on the electrode tip and the other part partially covered the droplet in transfer. This observation confirms that silicates were already present on the surface of the droplets before they entered the weld pool.

Next, the droplet entered the "hot" part of the weld pool, where the silicate islands could be seen floating outward to the periphery of the arc. The impact of the droplet into the molten

Table 4 - List of Wire Diameters and Linear Density of the Experimental Welding Wires Supplied by CTAS Air Liquide

\begin{tabular}{cc} 
Name of Wire (Diameter, in.) & Linear Density $(\mathrm{g} / \mathrm{m})$ \\
\hline A (0.045) & 7.8782 \\
A (0.052) & 10.3872 \\
B (0.047) & 8.1123 \\
C (0.035) & 4.8838 \\
D (0.047) & 8.6277 \\
E (0.055) & 8.1123
\end{tabular}
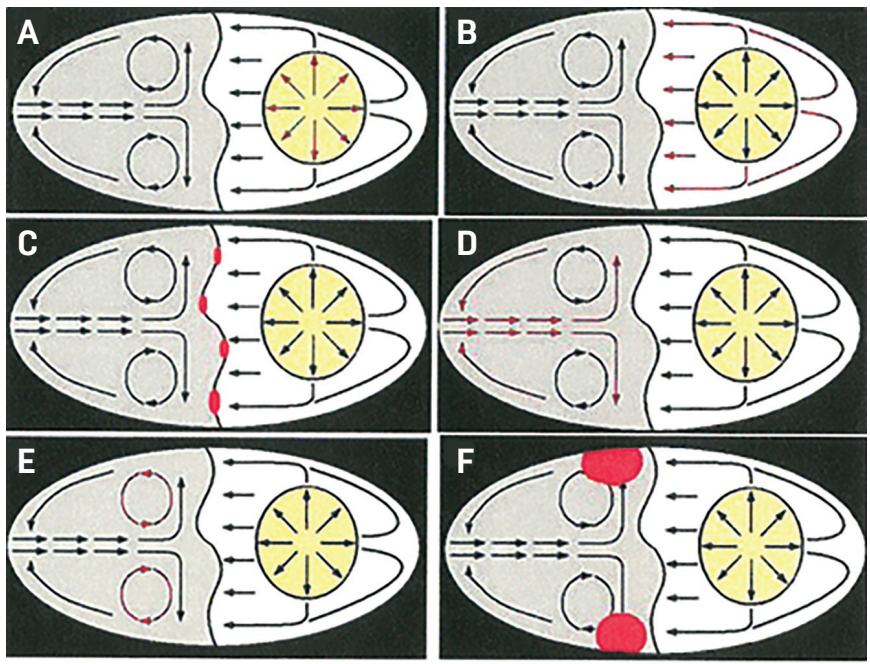

Part 2 of the weld pool Part 1 of the weld pool

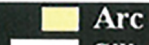

Silicate islands motion

Fig. 13 - Step-by-step schematic of the silicate flow on the surface of the weld pool: $A$ - Silicates radiate outward almost instantaneously from the arc; $B$ - the silicates are pushed to the hot/cold border by liquid flow; $\mathrm{C}$ - the silicates stay at the hot/cold border. Molten metal flow moves the silicates to the sides of the weld pool; $D$ - some silicates trail the weld pool along with an oxide layer. In this case, the Marangoni flow will push them to the trailing edge of the weld pool and then circulate them back to the hot/cold border; $E$ - silicates may also move circularly by the side of the weld pool, where silicate coalescence occurs; $\mathrm{F}$ - once the silicate island has grown sufficiently, it attaches to the side of the weld pool and solidifies.

pool created a liquid current that pushed the molten metal away from the center of the arc. Such behavior was predicted by the velocity field simulation work of Hu et al. (Ref. 18). Within the molten weld pool, alloying elements such as silicon and manganese are expected to form oxides from dissolved oxygen due to the lower solubility of oxygen in iron with decreasing temperature, which results in a larger amount of oxygen available for reaction. Liquid oxide particles are expected to float to the surface of the weld pool due to the density difference between the liquid oxides and the liquid iron. Oxide movement to the surface of the weld pool is also assisted by slag formation and fluid flow "stirring" in the hot part of the weld pool. The newly formed oxide particles will coalesce with those that arrived from the transferred molten droplets. Once a silicate has entered the cold part of the weld pool, less stir-

Table 5 - Welding Parameters Used in the Polarity Study (DCEP) (Asterisks indicate values that were calculated from estimations extracted from Fig. 3 for powder-cored wires of similar diameters.)

Wire Diameter (in.)

WFR (in./min)

Current $(A)^{*}$

Deposition Rate $(\mathrm{kg} / \mathrm{h})^{*}$

Heat/Filler Mass $(\mathrm{kJ} / \mathrm{g})^{*}$

\begin{tabular}{|c|c|c|c|c|}
\hline 0.045 & 160 & 260 & 7.9 & 6.9 \\
\hline 0.045 & 198 & 301 & 9.9 & 6.4 \\
\hline 0.045 & 260 & 368 & 13.0 & 5.9 \\
\hline 0.052 & 160 & 275 & 8.9 & 6.5 \\
\hline 0.052 & 198 & 319 & 11.1 & 6.0 \\
\hline 0.052 & 260 & 390 & 14.7 & 5.6 \\
\hline
\end{tabular}




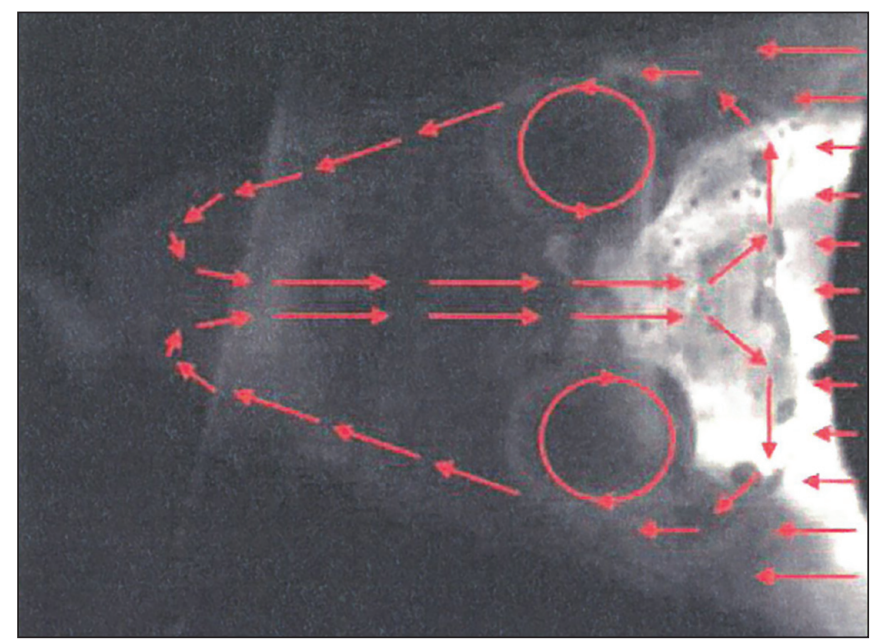

Fig. 14 - Still frame of the cold part of the weld pool. The flow pattern of the silicates has been overlaid in red.

ring is observed, causing the silicates to migrate to the edge or center of the weld pool where they then solidify - Fig. 8.

The high-speed video camera setup also revealed flow behavior of the silicate islands, which were present in every stage of the GMAW process. Silicate particles were observed to circulate and coalesce, eventually consolidating into larger silicate islands - Fig. 9. These larger silicate islands were then observed to attach to the side of the weld pool, where they then began to solidify - Fig. 10. An example of silicates solidified along the edge of the weld bead can be seen in Fig. 11.

Another type of solidification behavior observed involved solidification of silicate particles along the weld pool such that a line of silicates was formed along the weld toe. The silicate islands were also seen to attach to the trailing edge of the weld pool, which led to silicate solidification along the centerline of the weld.

The velocity of the liquid metal flow within the weld pool dictated the motion of silicates on the surface. From exhaustive examination of the high-speed videos of the GMAW weld pool, Fig. 12 was developed to describe the observed behavior of silicate flow on the surface of the weld pool. Part 1 (white) represents the hot part of the weld pool immediately under the welding electrode, while Part 2 (gray) represents the cold part of the weld pool. The hot part of the weld pool was observed to be shiny and free of slag, shielded only by the cover gas. Part 2, conversely, was observed to be covered by a layer of $\mathrm{FeO}$, which was determined by energy dispersive spectroscopy (EDS). Due to the abundance of Fe at the initial stage of melting, FeO formed first. FeO islands then collided in the melt pool with other oxide particles, which were seen in the highspeed video to have a different appearance than the $\mathrm{FeO}$ and formed at much smaller amounts than FeO. Once the silicate particles carried by the transferred droplet impacted the weld pool, they were quickly dispersed radially outward from the center of the arc. Liquid flow then pushed the silicates toward the trailing edge of the weld pool (i.e., to the border between the hot and cold part of the weld pool). The silicates only remained in this region for a very short period of time. Subsequently, the Marangoni (surface tension-driven) flow of the molten pool carried the silicate particles to the side of the weld pool, where they then followed two different trajectories. The first path followed the direction predicted by the surface ten-
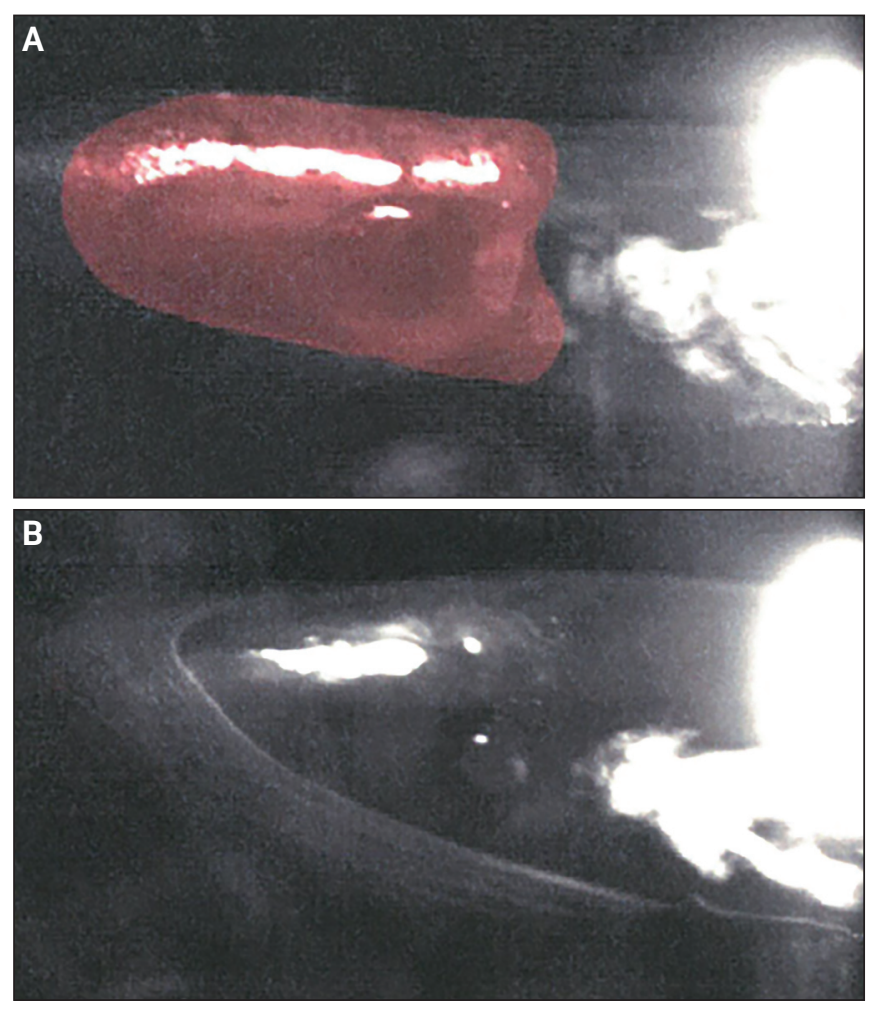

Fig. $15-$ Still frames of the cold part of the weld pool showing the following: $A-A$ weld pool with the presence of $a$ thick oxide mass at the trailing edge of the weld pool; $B-a$ weld pool without the thick oxide mass at the trailing edge.

sion gradient (Marangoni flow), according to which the silicates were first brought to the trailing edge of the weld pool and then carried back to the hot/cold border. The other trajectory was an eddy current path that rotated towards the sides of the weld pool. Within this eddy current, the silicates moved circularly and coalesced to form larger silicate islands. Observation shows that once a silicate island grows to a diameter of approximately $5 \mathrm{~mm}$, its flow becomes sluggish, and the silicate moves toward and attaches to the edge of the weld pool, which is colder and where the silicate island solidifies. These two paths have been illustrated in Fig. 13. In addition, Fig. 13 shows the silicates "radiating" outward from the arc location upon transference to the melt pool, after which they are pushed to the border between the hot/cold regions, where Marangoni flow can keep them until solidification completes. In the other case, silicates may also move circularly by the side of the weld pool, where they potentially coalesce and attach to the side of the weld pool. The flow paths in the cold part of the weld pool have been overlaid on a still frame of a GMAW weld pool in Fig. 14. High-speed video analysis assisted in the determination of the following preferred locations of the silicate islands: along the weld edge, the weld toe, and the weld centerline.

\section{Characterization of the Oxide Layer}

The formation of a continuous FeO layer on the surface of the solidifying weld pool is expected. The amount of oxide layer present decreased with decreasing oxidation potential of the shielding gas. Under certain experimental parameters, the 


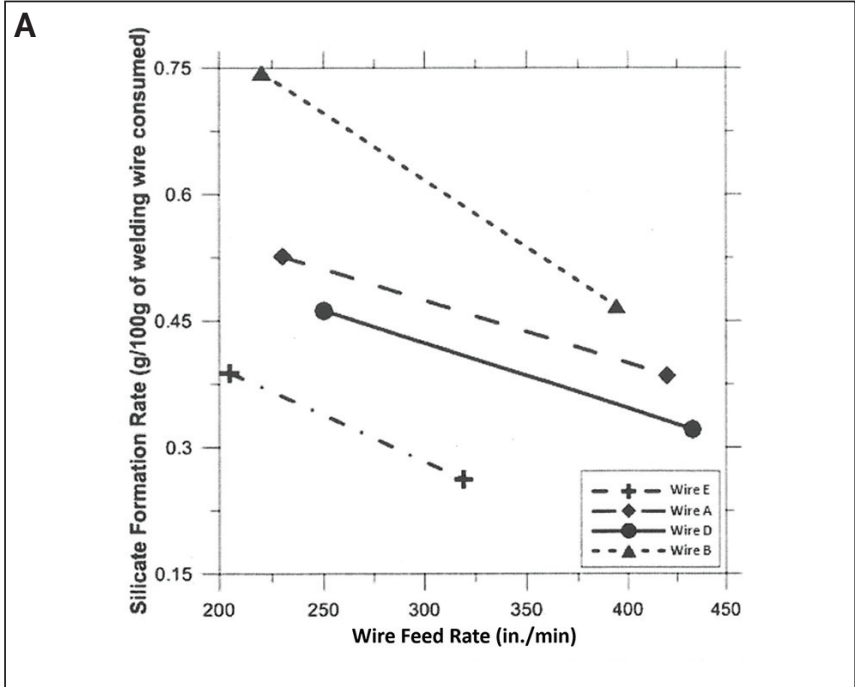

Fig. $16-$ A - Effect of wire feed rate on silicate formation rate for four welding wires of different composition with the same wire diameters; $B$ - effect of wire feed rate on the silicate formation rate of welding wires of different diameters for wire $A ; C$ - effect of wire diameter on SFR at varying voltages and wire feed rates for wire A. The WFR is given in the legend. \#3 indicates a higher voltage than \#2, which is a higher voltage than \#l.

oxide layer appeared thicker on the trailing part of the weld pool. Within the $\mathrm{FeO}$ layer, other oxides were expected to form and grow. These dispersed oxides comprised the silicate islands that can be seen by visual examination.

Energy dispersive spectroscopy was performed on the slag layer, which was revealed to be a layer of $\mathrm{FeO}$.

As mentioned previously, the weld pool can be divided into a "hot" and "cold" part, and the trailing edge was often covered by a thin oxide layer. However, in some systems, a third part of the weld was exhibited in the form of a thicker oxide layer, which had very low mobility on the surface of the weld pool, as shown in Fig. 15.

\section{Effect of Wire and Welding Parameters on SFR}

The data obtained from the experiments demonstrated a general trend of decreasing SFR with increasing wire feed rate - Fig. 16A. This result was unexpected at first examination given that increasing the wire feed rate would increase the welding current and heat input to the weld, which
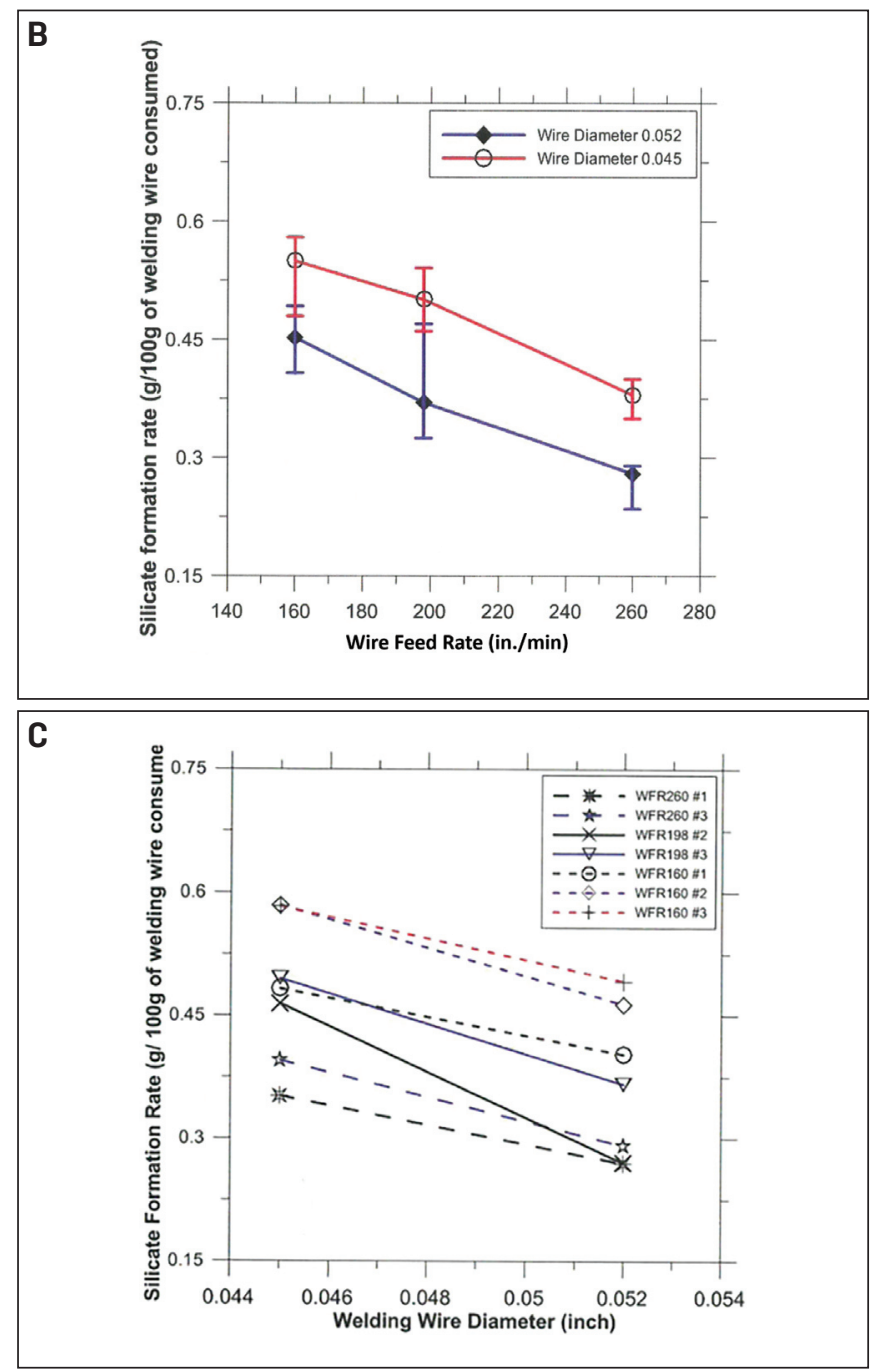

were expected to increase the rate of reaction of the following electrochemical and thermochemical reactions:

$$
\begin{gathered}
{[\mathrm{Si}] \rightarrow \mathrm{Si}^{4+}+4 e^{-}} \\
\mathrm{Si}^{4+}+2 \mathrm{O}^{2-} \rightarrow \mathrm{SiO}_{2} \\
{[\mathrm{Si}]+2[\mathrm{O}] \rightarrow \mathrm{SiO}_{2}}
\end{gathered}
$$

One hypothesis to explain this observation is that increasing the welding current causes more vaporization of the oxide layer, which decreases the amount of silicates formed on the surface (Ref. 19). An alternative explanation involves

Table 6 - Welding Parameters Used in the Polarity Study (DCEN) (Asterisks indicate values that were calculated from estimations extracted from Fig. 3 for powder-cored wires of similar diameters.)

\begin{tabular}{ccccc} 
Wire Diameter (in.) & WFR (in./min) & Current (A)* & Deposition Rate $(\mathrm{kg} / \mathrm{h})^{*}$ & Heat/Filler Mass $(\mathrm{kJ} / \mathrm{g})^{*}$ \\
\hline 0.045 & 160 & 352 & 7.9 & 9.9 \\
0.045 & 198 & 426 & 13.0 & 9.0 \\
0.045 & 260 & 548 & 8.9 & 8.8 \\
0.052 & 372 & 275 & 11.1 & 8.7 \\
0.052 & 198 & 451 & 14.7 & 8.5 \\
0.052 & 260 & 581 & 8.3
\end{tabular}



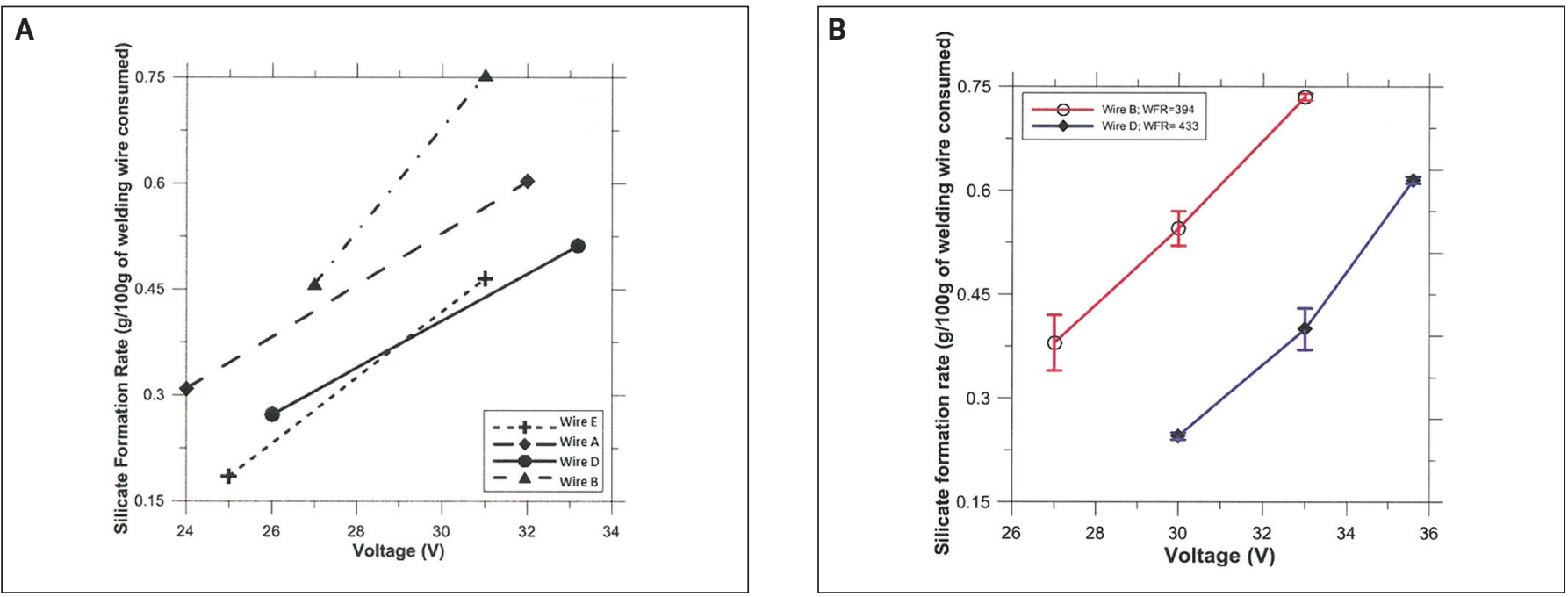

Fig. $17-A-$ Effect of voltage on SFR for four welding wires of different composition; B - effect of voltage on SFR for two welding wires of different composition and at two different wire feed rates.
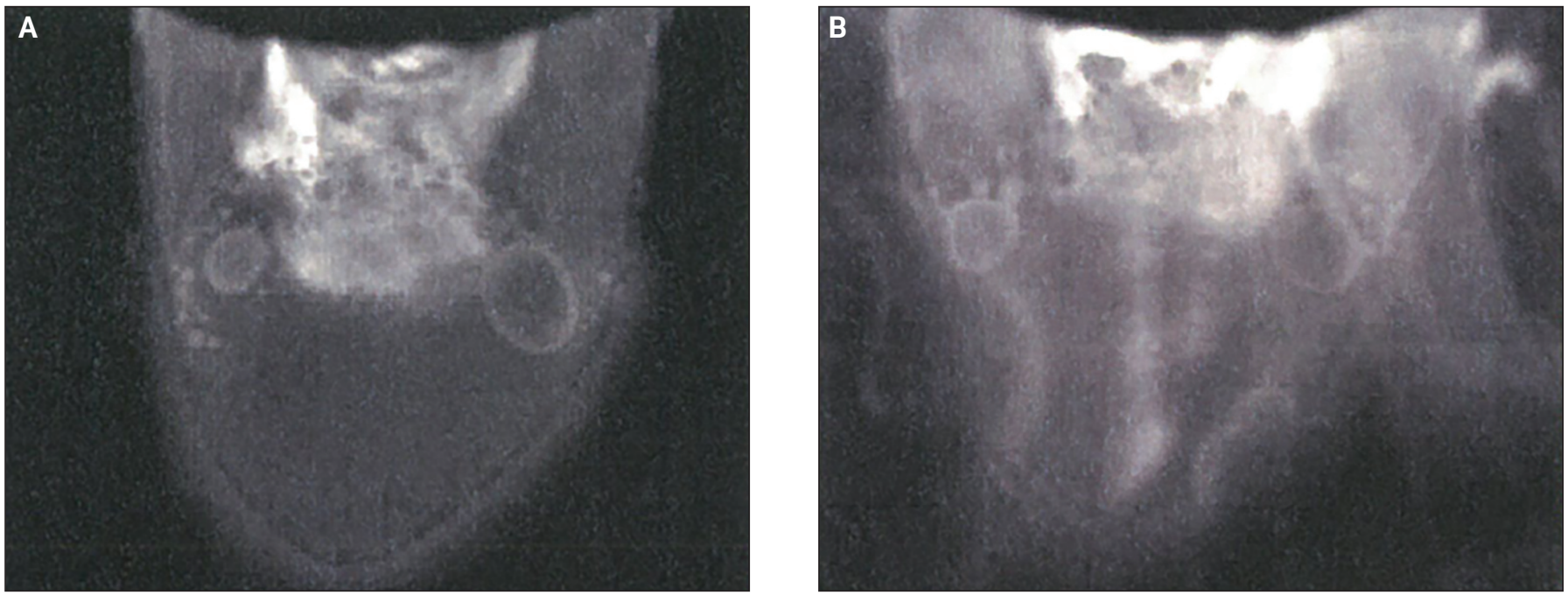

Fig. 18 - Still frames from high-speed recordings of GMAW taken from above the weld pool. These images show the cold part of the weld pool at A) $26 \mathrm{~V}$ and B) $36 \mathrm{~V}$. Silicate island population was larger in the higher voltage weld. The presence of the two silicate islands on both sides of the pool is due to the circulatory flow path of the silicates.

the increase in heat input due to increasing wire feed rate, which would cause more base metal dilution. Consequently, less silicon is expected to react with the oxygen diluted in the liquid metal, leading to decreased silicate formation. No attempts were made in this work to determine the amount of increased vaporization and base metal dilution.

Wire B was seen to produce more silicate islands, which can be attributed to the composition of the wire. Firstly, wire B contains a high amount of silicon to form siliconbased oxides (silicates). Additionally, the flux ingredients contained in each wire were already known to contain oxides, silicates, and metal powders. The metal powder particles might also possess a surface oxide layer, which could inhibit the deoxidizing reactions in the weld pool. During tubular electrode manufacturing, air may also be entrapped within the core, further increasing the oxygen content of the wire. All these potential sources of oxygen and the high amount of silicon can react to form a larger number of sili- cate islands. Wire A contained low silicon, and thus resulted in a low amount of silicate formation. The addition of microalloying elements and high $\mathrm{Mn}$ in wire D appears to have lowered the SFR although the wire silicon content was high. It is believed that the microalloying elements reduced the oxygen available for reaction with silicon to form silicate islands. Wire D contained the largest fraction of microalloying elements. Wire E also had large microalloying content with high $\mathrm{Mn}$ but the lowest Si content, therefore having the lowest SFR.

Using a larger wire diameter was found to decrease silicate formation rate as seen in Fig. 16B and C. For the same wire feed rate, a greater current can be carried by larger wire diameters (Ref. 20), which would increase the temperature in the arc and cause more vaporization of oxides (similar to increasing the wire feed rate). Additionally, a larger wire diameter possesses a lower current density, which reduces the extent of the electrochemical reactions occurring at the wire 

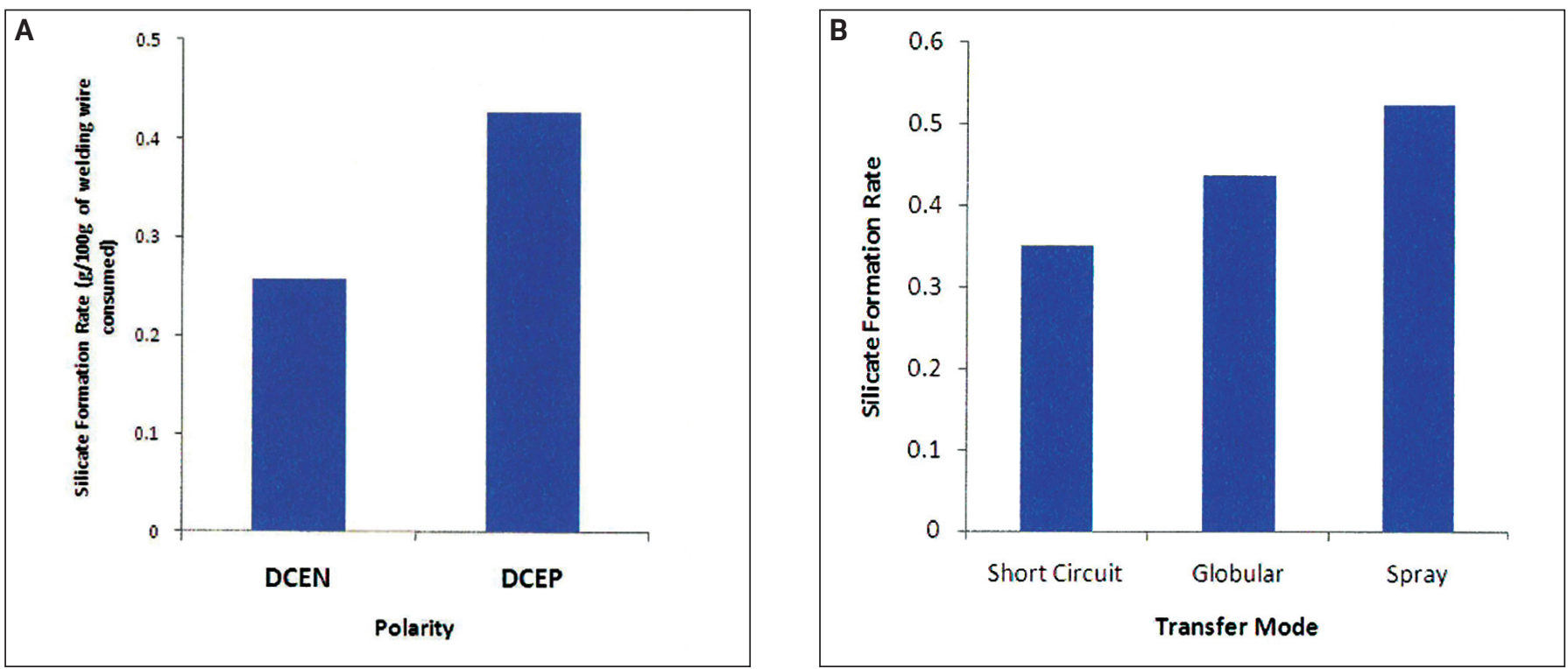

Fig. $19-A$ - Effect of polarity on SFR for a single wire composition; B - effect of transfer mode on SFR. Each transfer mode was achieved by adjusting welding voltage and WFR (e.g., high voltage and high WFR/current to achieve spray). The transfer modes were confirmed by analysis of the high-speed video recordings for each weld.

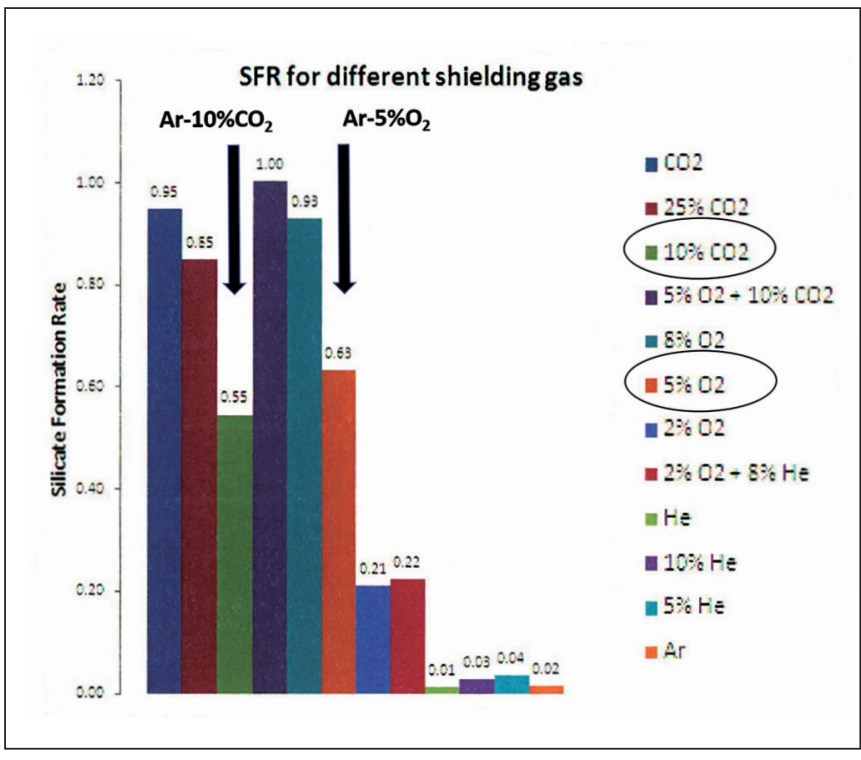

Fig. 20 - Silicate formation rate vs. shielding gas composition.

tip. Thus, to reduce the amount of silicate islands in GMA welds, larger-diameter electrodes would be preferred. The effects of voltage on silicate formation are shown in Fig. 17A and B. Increasing voltage while keeping other welding parameters constant lengthens the arc, which bestows a longer flight time for the molten droplets to traverse the arc, allowing for greater exposure of the molten droplets to oxidation before entering the weld pool.

Higher voltage also widens the arc at its base, which increased the size of the fusion zone, and a greater area of contact between the weld pool and the atmosphere was created. Finally, increasing the voltage raised the temperature of the weld pool, which allowed thermochemical reactions forming oxides and silicates to occur at a greater rate.
Analysis of the high-speed video recordings revealed that more silicate particles flow from the hot to the cold region of the weld pool for higher voltage values - Fig. 18. At $26 \mathrm{~V}$, no silicate islands were observed near the tail end of the solidified weld pool. Increasing the voltage to $36 \mathrm{~V}$, silicate islands could be seen in the vicinity of the edge of the weld pool tail end. Silicates were also seen to grow more quickly at higher voltages.

Welding speed was also examined for its effect on SFR. The general trend observed was decreasing SFR with increasing welding speed. As the welding speed increased, the weld pool elongated and became shallower, which provides a shorter time and smaller contact area for interaction of the liquid metal with the shielding environment. Lower energy is also imparted to the base metal, which lowers dilution of the weld, and smaller amounts of the alloying elements are available for the formation of silicates.

The effect of composition was examined with the CSM wires containing different levels of alloying elements. Increased Si, Al, and Mn content all increased SFR while Ti decreased SFR. As expected, the addition of Si had the strongest effect on increasing SFR. The addition of Ti decreased the SFR by providing a more preferential bonding partner for $\mathrm{O}_{2}$ than Si. Thus, more titanates were formed in the place of silicates. The relative greater stability of titanium-based oxides compared to silicon-based oxides support the observed SFR decrease with weld titanium addition. The addition of $\mathrm{Ni}$ also decreased the SFR. This observation is hypothesized to be due to the formation of $\mathrm{Ni}-\mathrm{SiC}$ such that less $\mathrm{Si}$ is available for silicate formation, but proving this hypothesis was not included in the scope of this work.

\section{Effect of Electrode Polarity on SFR}

The effects of polarity on SFR are demonstrated by Fig. 19A. Clearly, reversed polarity or electrode positive (DCEP) 

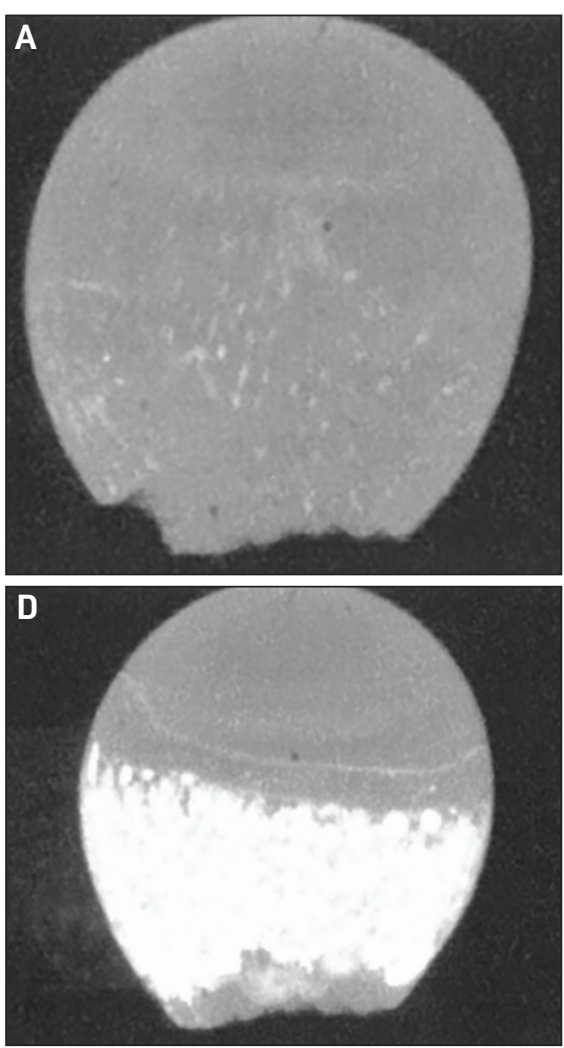
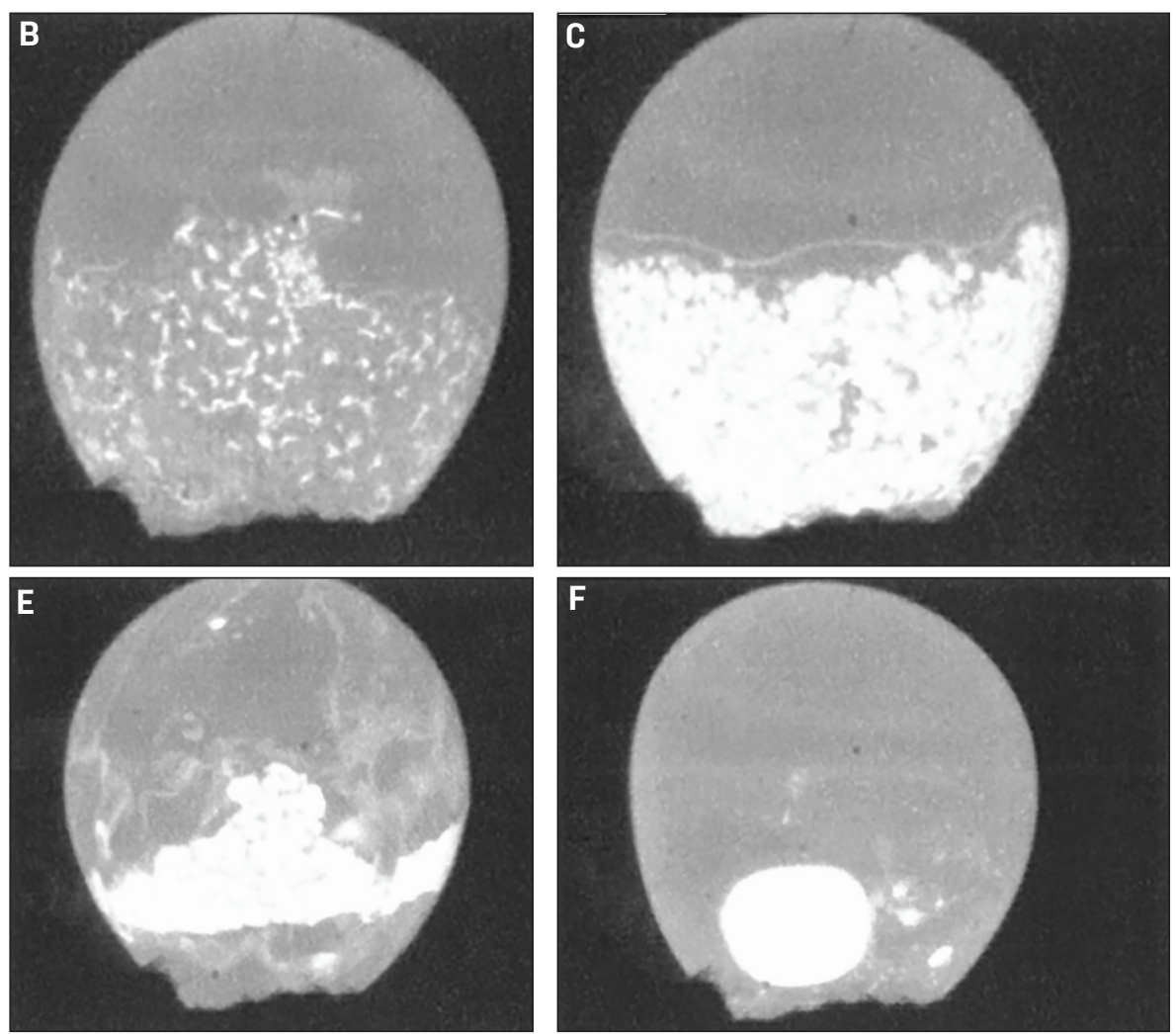

Fig. 21 - Selected still frames at different time lapses from the high-speed video recording of the oxidation of a molten droplet of wire A during electromagnetic levitation in an $\mathrm{Ar}-2 \% \mathrm{O}_{2}$ atmosphere. Duration of the experiment was $4 \mathrm{~s}$. The formation of oxides on the surface of the droplet can be seen.

caused higher SFRs than direct polarity or electrode negative (DCEN). In DCEP, electron flow toward the electrode will result in greater heating of the electrode. The partitioning of heat between the workpiece and the electrode in DCEP is generally taken to be $70 \%$ and $30 \%$, respectively. The effect as described earlier is then expected to also apply to the polarity effect. In DCEP, oxygen accumulated at the electrode while oxygen was removed at the workpiece, as shown by the following reactions:

$$
\begin{aligned}
& \text { Electrode: } \mathrm{O}^{2-}(\mathrm{slag}) \rightarrow \mathrm{O}(\text { metal })+2 \mathrm{e}^{-} \\
& \text {Workpiece: } \mathrm{O}(\text { metal })+2 \mathrm{e}^{-} \rightarrow \mathrm{O}^{2-}(\mathrm{slag})
\end{aligned}
$$

Additionally, formation of $\mathrm{Si}^{4+}$ ions at the electrode in DCEP occurred by

$$
\mathrm{Si} \rightarrow \mathrm{Si}^{4+}+4 \mathrm{e}^{-}
$$

These reactions imply that more oxygen was dissolved in the electrode tip, which likely provided more driving force for thermochemical reactions among oxygen, the silicon ions, and other alloying elements in the molten metal, thereby increasing the SFR.

\section{Effect of Transfer Mode on SFR}

The transfer mode describes the way by which molten metal was transported to the weld pool. Spray mode, which occurs under high voltage and high current, is a transfer mode in which the liquid metal droplets are of a smaller diameter than the electrode diameter. In the globular mode, the metal droplets being transferred have a larger diameter than the electrode diameter. In short-circuit transfer, the molten metal droplets were transferred directly from the electrode to the workpiece by direct contact with the weld pool. Short-circuit possessed the lowest heat input of the three transfer modes. Figure 19B shows the effect of transfer mode on SFR.

The spray transfer mode is shown to result in the highest SFR. This behavior was due to the higher surface area of molten metal interacting with the surrounding atmosphere as well as the higher heat present in this mode, which is likely facilitating thermochemical reactions between the molten droplets and any oxygen present.

\section{Effect of Shielding Gas Composition on SFR}

Figure 20 shows the effect of the composition of the shielding gas on the SFR. As expected, an inert gas such as pure Ar resulted in a low SFR. The SFR increased significantly with increasing $\mathrm{O}_{2}$ and $\mathrm{CO}_{2}$ content. Also expected was a lengthening of the arc as the $\mathrm{O}_{2}$ content increased (Ref. 21). With a higher concentration of $\mathrm{O}_{2}$, the arc was expected to stabilize and have a higher temperature due to the exothermic reactions between the $\mathrm{O}_{2}$ and other elements from the electrode (Ref. 21). The weld pool size also increased as a result, which allowed for a larger contact area for reactions between the pool and the arc atmosphere. It can also be seen from Fig. 20 that $\mathrm{Ar}-10 \% \mathrm{CO}_{2}$ 
exhibited a lower SFR than Ar-5\% $\mathrm{O}_{2}$. Onsøien (Ref. 22) attributes the lower oxygen equivalent of $\mathrm{Ar}-10 \% \mathrm{CO}_{2}$ than $\mathrm{Ar}$ $5 \% \mathrm{O}_{2}$ to the decomposition of $\mathrm{CO}_{2}$ molecules according to

$$
\mathrm{CO}_{2} \rightarrow \mathrm{CO}+\mathrm{O}
$$

That is, the formation of $\mathrm{CO}$ contributes additional shielding and diminishes the ability of oxygen to form oxides in the weld pool, thus lowering the SFR.

\section{Kinetics of Silicate Growth}

The following results and observations were made from the oxidation of steel droplets using the electromagnetic levitation system discussed in the experimental methods section. Analysis of the high-speed video recordings allowed for indepth observation of the reactions occurring on the droplet during levitation. Figure 21 shows a selection of frames extracted from a high-speed recording sequence of droplet levitation in an $\mathrm{Ar}-2 \% \mathrm{O}_{2}$ atmosphere. Initially, no oxidation was observed. Once the atmosphere reached the sample, a layer of oxide formed on the surface of the droplet and grew until a large portion of the droplet was covered by the layer - Fig. 21A-C. As oxidation progressed, the layer changed in morphology, as seen in Fig. 21D and E. Further progression led to the coalescence of oxide islands on the surface of the droplet - Fig. 21F. By similar analysis of droplet levitation under different oxidizing atmospheres, it was found that as oxidation potential of the shielding gas increased, the initial amount of oxide on the droplet also increased. Under an $\mathrm{Ar}-8 \% \mathrm{O}_{2}$ atmosphere, nearly the entire surface of the droplet was quickly (on the order of thousandths of seconds) covered by the oxide layer. Also, the sizes of the final oxide islands increased with increasing oxygen potential.

Figure 22 shows the evolution of the amount of oxide layer on the surface of the droplet with oxidation time. As expected, an increase in levitation time increased the surface area covered by oxides. Given that the longest oxidation times tested were several seconds, which is unrealistic compared against the short solidification time in welding, these tests represent extreme cases of silicate coverage.

From SEM/EDS analysis of the droplets oxidized for different lengths of time, it was seen that the first oxide layers formed on the wire A droplet substrate were iron oxide, and the final islands seen (after the change of morphology of the first oxide layer) were silicates. This behavior was likely due to the initial abundance of iron in the oxidizing environment, which formed the first oxide layer. Subsequent oxidation of other elements, such as titanium and silicon, was followed by coalescence of these oxides, which formed the silicates. For inert gas atmospheres, no oxides were observed to form.

These same experiments were repeated with an Ar-10\% $\mathrm{CO}_{2}$ gas, which has a similar oxygen potential as the Ar-5\% $\mathrm{O}_{2}$ gas (based on data from Onsøien [Ref. 22]). Comparing the oxidation behavior under a $5 \% \mathrm{O}_{2}$ atmosphere vs. a $10 \%$ $\mathrm{CO}_{2}$ atmosphere, the droplet in the $10 \% \mathrm{CO}_{2}$ atmosphere exhibited faster formation of surface oxides, which continued to form until the entire droplet was covered. In the $5 \% \mathrm{O}_{2}$ atmosphere, the oxides never attained full coverage of the droplet surface, and the interstitial oxygen percentage was observed to remain nearly constant regardless of oxidation

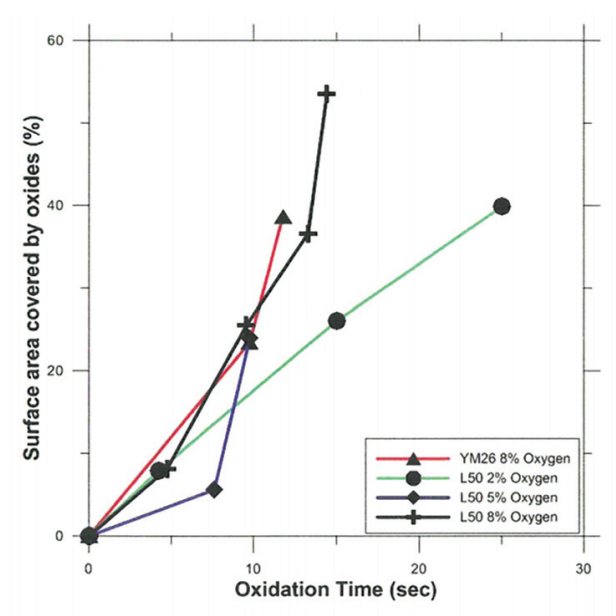

Fig. 22 - Surface area \% of the liquid droplet covered by oxides vs. oxidation time.

time, which indicates very favorable oxidation kinetics in this case. In the case of the $10 \% \mathrm{CO}_{2}$ atmosphere, longer oxidation times exhibited less interstitial oxygen. This observation likely indicates an initial rapid oxidation of the sample during which the surface oxide forms. Following the formation of the surface oxide, oxygen exchange between the droplet and the atmosphere was limited. The difference in behavior between the two atmospheres can possibly be explained by the decomposition of $\mathrm{CO}_{2}$ into $\mathrm{O}$ and $\mathrm{CO}$. If $\mathrm{CO}_{2}$ dissociates into $\mathrm{CO}$ and $\mathrm{O}$, the $\mathrm{CO}$ could form a protective layer around the droplet that would slow oxidation, actually acting as a shielding gas (Ref. 23). In this case, only the alloying elements directly on the surface can react with the oxygen to form a surface oxide layer. In $\mathrm{O}_{2}$-containing atmospheres, the oxygen atoms can dissolve in the molten metal and react with alloying elements in the bulk of the droplet. The oxides formed in the bulk then float to the surface and coalesce there with other oxides to form large silicate islands.

\section{Conclusion}

In this work, high-speed video recording was used for insitu observation of oxide formation during welding and electromagnetic levitation. The effects of welding parameters on silicate formation rate were observed. The effects of atmosphere composition, oxidation time, and metal droplet composition on silicate formation kinetics were also studied.

Formation of silicate islands during GMAW are the result of oxidation of alloying elements, including $\mathrm{Si}, \mathrm{Mn}, \mathrm{Ti}$, and $\mathrm{Fe}$, that are present in the welding system. Due to density differences between liquid steel and the oxides, the oxides float to the surface until solidification. Oxide mixing with pure $\mathrm{SiO}_{2}$ at the surface leads to the formation of silicate islands.

Silicates were seen to already be present on the surface of detached droplets from the melted electrode tip during welding. These silicates were incorporated into the liquid metal once the droplets fell into the weld pool. Fast liquid flow in the hot part of the weld pool ejected the molten silicates to the cold region of the pool. Once outside the influence of the weld- 
ing arc, Marangoni flow directed the silicate particles to the sides and rear of the weld pool, where they take on a rotating flow pattern, which drives coalescence and growth of large silicate islands. Once the silicate islands grow sufficiently, the islands generally attach to the side of the weld pool and solidify. Depending on the flow pattern in the weld pool and the size of the silicate islands, the silicates can solidify along the edges (for larger silicate islands) or along the centerline of the weld.

The most significant effect on silicate formation rate during welding was found by adjusting the $\mathrm{O}_{2} / \mathrm{CO}_{2}$ composition of the shielding gas; the welding voltage; and the $\mathrm{Si}, \mathrm{Mn}$, and Ti content of the welding wire. Increasing these parameters increased the silicon formation rate.

Regarding the kinetics of silicate growth, increasing oxidation time increased the surface area occupied by oxides. Increased oxidation potential of the shielding atmosphere also increased the coverage of oxides. A thin iron oxide layer was seen to form on the surface and then mix and coalesce to form a thicker oxide layer. An intermediate oxide layer was seen to form between the silicate islands and the metal. For an atmosphere containing $\mathrm{O}_{2}$ and an atmosphere containing $\mathrm{CO}_{2}$ at the same oxidation potential, oxide formation proceeded differently due to the dissociation of $\mathrm{CO}_{2}$ to $\mathrm{O}$ and $\mathrm{CO}$, with the $\mathrm{CO}$ acting as a shielding gas and decreasing the amount of oxidation of the liquid metal. The levitation work indicates that the growth of the silicate can be suppressed with shielding gases of a sufficiently low oxidation potential, which would likely be the best option to prevent the islands from forming. Combined with adjusting the composition of the fillers within specifications, it is likely that silicate island formation can be prevented.

\section{Acknowledgment}

The authors wish to acknowledge the support of Air Liquide Technical Centre for Welding Applications for their support in the completion of this work.

\section{References}

1. Bennett, H., and Hawley, W. G. 1965. Methods of Silicate Analysis. Academic Press for the British Ceramic Research Association.

2. Seo, J. S., Kim, H. J., and Lee, C. 2013. Effect of Ti addition on weld microstructure and inclusion characteristics of bainitic GMA welds. ISIJ International 53(5): 880-886. DOI: 10.2355/ isijinternational.53.880

3. Douglas, B. A. 1989. Nonmetallic inclusions in HSLA steel weldments. PhD thesis, Monterey, Calif., Naval Postgraduate School.

4. Li, P., Svensson, L.-E., Nylén, P., Markocsan, N., and Klement, U. 2012. Characterization of cold lap defects in tandem arc MAG welding. Welding in the World 56(9-10): 20-25. DOI: 10.1007/ BF03321377

5. Li, P. G., Svensson, L.-E., and Markocsan, N. 2012. Influence of oxides on cold lap formation in tandem GMAW. Science and Technology of Welding and Joining 17(8): 643-648. DOI: 10.1179/ 1362171812 Y.0000000057

6. Quintana, M. A., McLane, J., Babu, S. S., and David, S. A. 2001. Inclusion formation in self-shielded flux cored arc welds. Welding Journal 80(4): 98-s to 105-s.
7. Thewlis, G, and Milner, D. R. 1977. Inclusion formation in arc welding. Welding Journal 56(9): 281-s to 288-s.

8. Leduey, B. 2007. Fil fourre de soudage sans laitier et a forte teneur en silicium pour soudage des aciers ferritiques.

9. Liu, S., and Olson, D. L. 1987. The influence of inclusion chemical composition on weld metal microstructure. Journal of $\mathrm{Ma}$ terials Engineering 9(3): 237-251. DOI: 10.1007/BF02834144

10. Grong, O., Siewert, T. A., Martins, G. P., and Olson, D. L. 1986. A model for the silicon-manganese deoxidation of steel weld metals. Metallurgical Transactions A 17(10): 1797-1807. DOI: 10.1007/BF02817277

11. Hong, T., Pitscheneder, W., and DebRoy, T. 2014. Quantitative modelling of motion, temperature gyrations, and growth of in clusions in weld pool. Science and Technology of Welding and Joining 3(1): 33-41. DOI: 10.1179/stw.1998.3.1.33

12. Mitra, U., and Eagar, T. W. 1991. Slag-metal reactions during welding: Part II. Theory. Metallurgical Transactions B 22(February): 73-81. DOI: 10.1007/BF02672529

13. Mitra, U., and Eagar, T. W. 1991. Slag-metal reactions during welding: Part III. Verification of the theory. Metallurgical Transactions B 22(1): 83-100. DOI: 10.1007/BF02672530

14. Kou, S. 2003. Welding Metallurgy, Second Edition. John Wiley \& Sons.

15. Richardson, F. D. 1974. Physical Chemistry of Melts in Metallurgy. London; New York: Academic Press (Elsevier).

16. Reisgen, U., Pipinikas, A., and Sharma, R. 2017. Influence of boundary conditions on slag formation in GMA welding of AHSS steels for automotive applications. Steels in Cars and Trucks, August 2018. Amsterdam.

17. Wang, F., Hou, W. K., Hu, S. J., Kannatey-Asibu, E., Schultz, W. W., and Wang, P. C. 2003. Modelling and analysis of metal transfer in gas metal arc welding. Journal of Physics D: Applied Physics 36(9): 1143-1152. DOI: 10.1088/0022-3727/36/9/313

18. Hu, J., Guo, H., and Tsai, H. L. 2008. Weld pool dynamics and the formation of ripples in 3D gas metal arc welding. International Journal of Heat and Mass Transfer 51(9-10): 2537-2552. DOI: 10.1016/j.ijheatmasstransfer.2007.07.042

19. Valensi, F. 2007. Contribution à l'étude des phénomènes liés aux effets anodiques et cathodiques en soudage MIG-MAG. PhD thesis, Université d'Orléans.

20. Modenesi, P. J., and de Avelar, R. C. 1999. The influence of small variations of wire characteristics on gas metal arc welding process stability. Journal of Materials Processing Technology 86 (1-3): 226-232. DOI: 10.1016/S0924-0136(98)00315-X

21. Pires, I., Quintino, L., and Miranda, R. M. 2007. Analysis of the influence of shielding gas mixtures on the gas metal arc weld ing metal transfer modes and fume formation rate. Materials and Design 28(5): 1623-1631. DOI: 10.1016/j.matdes.2006.02.012

22. Onsøien, M. I., Liu, S., and Olson, D. L. 1996. Shielding gas oxygen equivalent in weld metal microstructure optimization. Welding Journal 75(7): 216-s to 224-s.

23. Grong, O., and Matlock, D. K. 1986. Microstructural development in mild and low-alloy steel weld metals. International Metals Reviews 31(1): 27-48. DOI: 10.1179/imtr.1986.31.1.27

RICHARD DERRIEN, ETHAN MICHAEL SULLIVAN (esullivan@mines.edu), and STEPHEN LIU are with the Center of Welding, Joining \& Coating Research, Colorado School of Mines, Golden, Colo. ELODIE MOINE and FRANCIS BRIAND are with Air Liquide Technical Centre for Welding Applications, Paris, France. 